\title{
Low frequency dielectric relaxation processes and ionic conductivity of montmorillonite clay nanoparticles colloidal suspension in poly(vinyl pyrrolidone)-ethylene glycol blends
}

\author{
R. J. Sengwa*, S. Choudhary, S. Sankhla \\ Dielectric Research Laboratory, Department of Physics, J N V University, Jodhpur - 342005, India
}

Received 22 August 2008; accepted in revised form 26 September 2008

\begin{abstract}
The dielectric dispersion behaviour of montmorillonite (MMT) clay nanoparticles colloidal suspension in poly(vinyl pyrrolidone)-ethylene glycol (PVP-EG) blends were investigated over the frequency range $20 \mathrm{~Hz}$ to $1 \mathrm{MHz}$ at $30^{\circ} \mathrm{C}$. The $0,1,2,3,5$ and $10 \mathrm{wt} \% \mathrm{MMT}$ clay concentration of the weight of total solute (MMT+PVP) were prepared in PVP-EG blends using EG as solvent. The complex relative dielectric function, alternating current (ac) electrical conductivity, electric modulus and impedance spectra of these materials show the relaxation processes corresponding to the microBrownian motion of PVP chain, ion conduction and electrode polarization phenomena. The real part of ac conductivity spectra of these materials obeys Jonscher power law $\sigma^{\prime}(\omega)=\sigma_{d c}+A \omega^{n}$ in upper frequency end of the measurement, whereas dispersion in lower frequency end confirms the presence of electrode polarization effect. It was observed that the increase of clay concentration in the PVP-EG blends significantly increases the ac conductivity values, and simultaneously reduces the ionic conductivity relaxation time and electric double layer relaxation time, which suggests that PVP segmental dynamics and ionic motion are strongly coupled. The intercalation of EG structures in clay galleries and exfoliation of clay sheets by adsorption of PVP-EG structures on clay surfaces are discussed by considering the hydrogen bonding interactions between the hydroxyl group $(-\mathrm{OH})$ of EG molecules, carbonyl group $(\mathrm{C}=\mathrm{O})$ of $\mathrm{PVP}$ monomer units, and the hydroxylated aluminate surfaces of the MMT clay particles. Results suggest that the colloidal suspension of MMT clay nano particles in the PVP-EG blends provide a convenient way to obtain an electrolyte solution with tailored electrical conduction properties.
\end{abstract}

Keywords: nanocomposites, PVP-EG blend, MMT clay colloidal suspension, dielectric spectroscopy, electrical conductivity

\section{Introduction}

Miscibility of PVP with EG solvent is related to the formation of hydrogen bonds (H-bond) between carbonyl groups $(\mathrm{C}=\mathrm{O})$ of the repeating units of the PVP chain and hydroxyl groups $(-\mathrm{OH})$ of the EG molecules. The PVP-EG complexation results the breaking of some of the H-bonded self-associated EG structures. It was confirmed that no more than 27 EG molecules bearing 54 hydroxyl groups involve themselves in complex formation per 100 monomer units of PVP molecules [1], which shows the presence of uncomplexed $\mathrm{H}$-bonded pure EG structures in the PVP-EG blends. The pressure-sensitive adhesive properties of PVP-EG blends find its extensive use as a reservoir vehicle controlling the rate of drug delivery $[2,3]$. Besides the other parameters, in general, the rate of drug release in polymeric blend matrix depends on the polymer chain dynamics [3] and ionic conduction process [4]. The loading of MMT clay in hydrophilic polymer matrix enhances its potential application in medicine and pharmacy [5] and also in electrolytes [6-9]. 
The polymeric grade MMT clay is 2:1 phyllosilicate, which is also called inorganic polymer, and chemically it is a metal silicate [10]. The dispersion of small amount of MMT clay in a suitable polymeric solvent has swelling properties. Swelling of the clay is mainly due to solvent intercalation (absorption) in the clay galleries, and also because of the adsorption of solvent molecules on the hydroxylated aluminate clay surfaces through H-bond interactions, which results the clay exfoliation. The intercalated and exfoliated clay sheets in polymeric solvent results the organic-inorganic nanocomposites of highly complicated structures, which is responsible for the improved thermal, mechanical, gas barrier and electrical properties of the polymer-clay nanocomposites (PCNs) [6-18]. The investigation of broadband dielectric spectroscopy (BDS) of the materials covers nowadays the extraordinary spectral range from $10^{-6}$ to $10^{12} \mathrm{~Hz}$ [19]. The BDS frequency ranges from $10^{-1}$ to $10^{-3} \mathrm{~Hz}$ and $10^{-4}$ to $10^{-6} \mathrm{~Hz}$ are denoted by very low and ultra low (quasi-dc) spectrums respectively, whereas $\sim 10^{0}-10^{4} \mathrm{~Hz}, \sim 10^{5}-10^{7} \mathrm{~Hz}$ and $\sim 10^{8}-10^{12} \mathrm{~Hz}$ are known as low frequency, middle frequency and high frequency spectrums, respectively. The BDS characterization of the dielectric materials provide the confirmative information on the intra- and intermolecular dynamics, the degree of intermolecular $\mathrm{H}$-bond interactions, cooperativity between guest and host molecules, and ionic and electrode polarization processes related to the molecular structures $[19,20]$. The BDS study of PVP-EG blends over the frequency range $20 \mathrm{~Hz}$ to $20 \mathrm{GHz}$ are described by the sum of three relaxation processes with the contribution of dc conductivity [21]. The low frequency process (1-process) for PVP-EG blends is caused by electrode polarization and ionic conduction phenomena [21-24]. The middle frequency process (m-process) is observed corresponding to the micro-Brownian motion (local chain motion) of the PVP chain, whose time is of the order of about $10^{-6} \mathrm{~s}[21,22]$. The repeat unit of PVP has a bulky pyrrolidone ring as side group that the local chain motion need a large free volume and has large hindrance to its motion. The high frequency process (h-process) of the PVP-EG blends in the microwave frequency region occurs due to reorientation of EG molecules, which takes the duration of approximately $10^{-9} \mathrm{~s}[21,25-27]$.
In this paper, we study the dielectric spectroscopy over the frequency range $20 \mathrm{~Hz}$ to $1 \mathrm{MHz}$ of montmorillonite (MMT) clay colloidal suspension in the PVP-EG blend. The objective of present paper is to confirm the effect of clay concentration on the PVP micro-Brownian motion, and ionic conductivity and electrode polarization relaxation processes in the MMT clay loaded PVP-EG blends. All the intensive quantities, namely, complex relative dielectric function $\varepsilon^{*}(\omega)$, electrical modulus $M^{*}(\omega)$ and electrical conductivity $\sigma^{*}(\omega)$, and extensive quantity i.e., complex impedance $Z^{*}(\omega)$, which is inverse of complex admittance $Y^{*}(\omega)$ were used to explore the low frequency processes contributed in the electrical/dielectric properties of the coexisting phases of colloidal suspension of the MMT clay (inorganic polymer) in the PVP-EG blend (organic polymer solvent).

\section{Experimental}

\subsection{Materials}

Laboratory grade poly(vinyl pyrrolidone) (PVP) of weight average molecular weight $\left(M_{w}\right) 24000 \mathrm{~g} / \mathrm{mol}$ was obtained from S.D. Fine-Chem, India. Ethylene glycol (EG) of laboratory grade was obtained from E. Merck, India. Polymer grade hydrophilic montmorillonite (MMT) clay (Nanoclay, PGV), a product of Nanocor ${ }^{\circledR}$, was purchased from SigmaAldrich, USA. The $\mathrm{Na}^{+}$-MMT clay is white in colour, and have $145 \mathrm{meq} / 100 \mathrm{~g}$ cation exchange capacity (CEC), $\sim 1 \mathrm{~nm}$ thickness sheets (platelets), 150-200 aspect ratio (length/width), $2.6 \mathrm{~g} / \mathrm{cc}$ specific gravity, and $9-10 \mathrm{pH}$ value on 5\% dispersion.

\subsection{Preparation of MMT clay colloidal suspension in PVP-EG blends}

For preparation of the MMT clay nanoparticles colloidal suspension, $10 \mathrm{wt} \%$ (weight fraction) of total solute (MMT clay + PVP) (1.5 g) was added in the EG solvent (13.5 g) in two steps procedure. Firstly, the PVP-EG blends of varying concentration were prepared by dissolving the required amounts of the PVP solute $(1.5,1.485,1.47,1.455,1.425$, and $1.35 \mathrm{~g}$ ) in EG solvent. Afterwards, the respective amounts of $0,1,2,3,5$ and $10 \mathrm{wt} \%$ MMT clay concentration $(0.00,0.015,0.03,0.045,0.075$ and $0.15 \mathrm{~g})$ of the total weight of the solute $(1.5 \mathrm{~g})$ were added in the respective prepared PVP-EG blends 
for the preparation of varying clay concentration colloidal suspension in PVP-EG blends. The presence of hydrated $\mathrm{Na}^{+}$cations makes the hydrophilic behaviour of MMT clay galleries so that polar hydrophilic PVP-EG blends can mix without the need of organic modification of the clay sheets. The MMT clay nanoparticles (also called nanoplatelets) colloidal dispersion (intercalation, exfoliation and tactoids) at room temperature were achieved by vigorous magnetic stirring of the samples for $2 \mathrm{hrs}$ at $50^{\circ} \mathrm{C}$, and immediately after this process, the colloidal samples were used for their dielectric characterization.

\subsection{Dielectric measurements}

Agilent 4284A precision LCR meter and Agilent 16452A liquid dielectric test fixture with a four terminals nickel-plated cobal (an alloy of $17 \%$ cobalt $+29 \%$ nickel $+54 \%$ iron) electrodes of diameter $40 \mathrm{~mm}$ and spacing $0.5 \mathrm{~mm}$, were used for the capacitance and resistance measurement in the frequency range $20 \mathrm{~Hz}$ to $1 \mathrm{MHz}$. The capacitances $C_{0}$ and $C_{P}$ without and with sample, respectively and equivalent parallel resistance $R_{p}$ with sample, were measured for the determination of all the dielectric/electrical function of the prepared materials. The short circuit compensation of the cell and its correction coefficient were considered to eliminate the effect of stray capacitance during the evaluation of the frequency dependent values of complex dielectric function. All measurements were made at $30^{\circ} \mathrm{C}$ and the temperature was controlled by Thermo-Haake DC10 controller.

The complex dielectric function $\varepsilon^{*}(\omega)$ of the materials is determined from the Equation (1) [28]:

$\varepsilon^{*}(\omega)=\varepsilon^{\prime}-j \varepsilon^{\prime \prime}=\alpha\left(\frac{C_{P}}{C_{0}}-j \frac{1}{\omega C_{0} R_{P}}\right)$

where $\omega=2 \pi f$ is the angular frequency and $\alpha$ is the correction coefficient of the cell.

Figure 1 shows the frequency dependent spectra of the real part of the relative dielectric function $\varepsilon^{\prime}$, dielectric loss $\varepsilon^{\prime \prime}$, and loss tangent $\tan \delta=\varepsilon^{\prime \prime} / \varepsilon^{\prime}$ with varying MMT clay concentration colloidal suspension in the PVP-EG blend, at $30^{\circ} \mathrm{C}$. The $\tan \delta$ spectra has the peak value corresponding to the electrode polarization (EP) relaxation frequency $f_{E P}$, which is used to evaluate the EP relaxation time

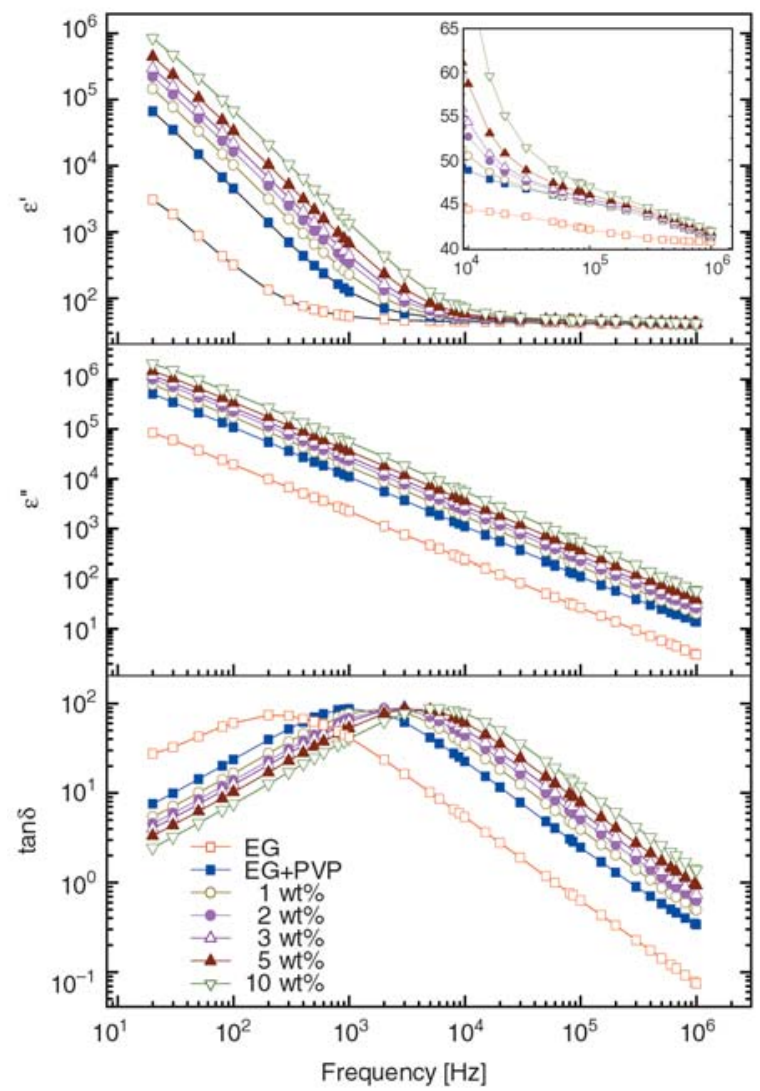

Figure 1. Frequency dependence of real part of dielectric function $\varepsilon^{\prime}$ and loss $\varepsilon^{\prime \prime}$, and loss tangent $\tan \delta$ of MMT clay nanoparticles colloidal suspension in PVP-EG blends at varying clay concentration. Inset shows that the gradual shift in $\varepsilon^{\prime}$ dispersion of the m-process corresponds to the local chain motion of PVP towards higher frequencies with increase of the clay concentration in the PVP-EG blends.

$\tau_{E P}=\left(2 \pi f_{E P}\right)^{-1}[22-24,29-33]$. The correct value of $f_{E P}$ of these materials were determined by $\tan \delta(f)$ data fit using the Origin ${ }^{\circledR}$ non-linear curve fitting tool.

The frequency dependent real part $\sigma^{\prime}$ and the imaginary part $\sigma^{\prime \prime}$ of the alternating current (ac) complex conductivity $\sigma^{*}(\omega)$ of the samples were obtained from the Equation (2) [20, 34]:

$$
\sigma^{*}(\omega)=\sigma^{\prime}+j \sigma^{\prime \prime}=j \omega \varepsilon_{0} \varepsilon^{*}(\omega)=\omega \varepsilon_{0} \varepsilon^{\prime \prime}+j \omega \varepsilon_{0} \varepsilon^{\prime}
$$

where $\varepsilon_{0}\left(8.854 \cdot 10^{-12} \mathrm{~F} \cdot \mathrm{m}^{-1}\right)$ is free space dielectric constant. Figure 2 shows the $\sigma^{\prime}$ spectra of the investigated MMT clay colloidal suspension in the PVP-EG blends.

Considering the charges as the independent variable, conductivity relaxation effects can be suitably 


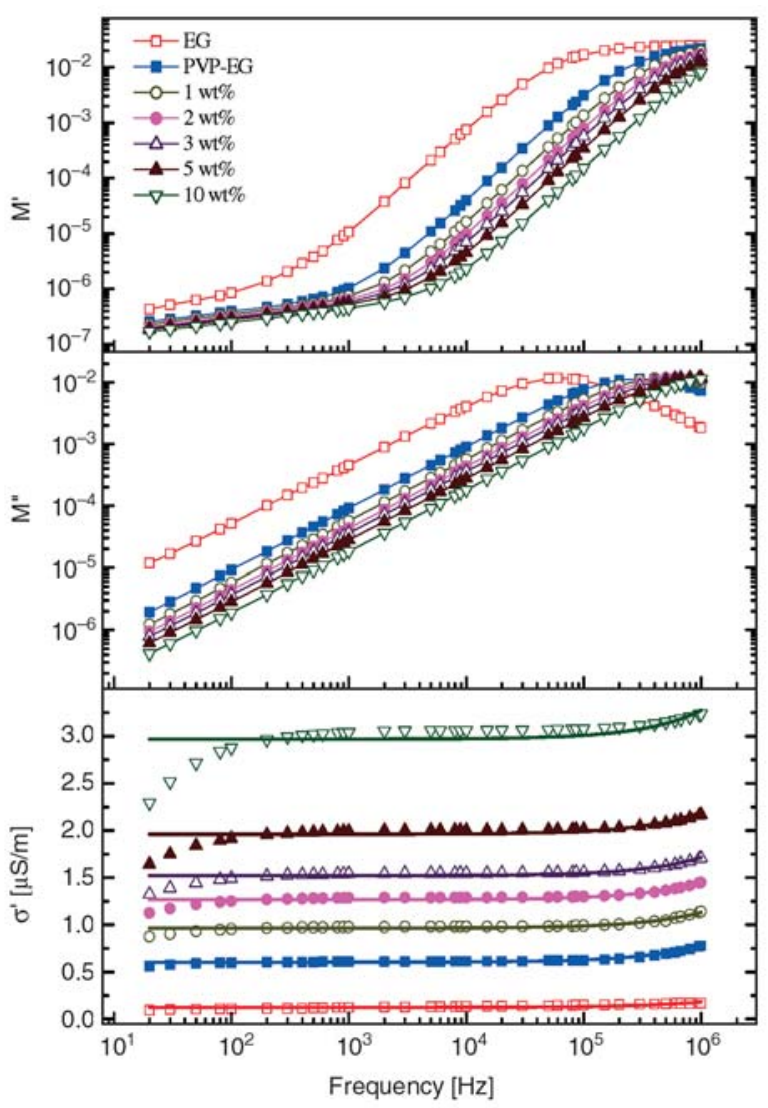

Figure 2. Frequency dependence of real part of electric modulus $M^{\prime}$ and loss $M^{\prime \prime}$, and real part of ac conductivity $\sigma_{a c}$ of MMT clay nanoparticles colloidal suspension in PVP-EG blends at varying clay concentration. The continuous solid line in $\sigma^{\prime}$ spectra represents the fit of experimental data to the power law $\sigma^{\prime}(\omega)=\sigma_{d c}+A \omega^{n}$.

analyzed within the modulus formalism in terms of a dimensionless quantity, called electric modulus $M^{*}(\omega)$. The frequency dependent values of $M^{*}(\omega)$ is obtained from the Equation (3) [8, 29, 30, 35]:

$$
M^{*}(\omega)=\frac{1}{\varepsilon^{*}(\omega)}=M^{\prime}+j M^{\prime \prime}=\frac{\varepsilon^{\prime}}{\varepsilon^{\prime 2}+\varepsilon^{\prime \prime 2}}+j \frac{\varepsilon^{\prime \prime}}{\varepsilon^{\prime 2}+\varepsilon^{\prime \prime 2}}
$$

The main advantage of this formulation is that, the space charge effects often do not mask the features of the spectra, owing to suppression of high capacitance phenomena in $M^{\prime \prime}(f)$ plots. The spectra of the evaluated values of the real part $M^{\prime}$ and the imaginary part $M^{\prime \prime}$ of the electric modulus of varying MMT clay concentration colloidal suspension in the PVP-EG blend is also shown in Figure 2, alongwith the conductivity spectra. The $M^{\prime \prime}(f)$ spectra of these materials have peaks, and the frequency $f_{\sigma}$ corresponding to these peaks is related to the most probable ionic conductivity relaxation time $\tau_{\sigma}[29]$. The exact values of $f_{\sigma}$ were determined from the fit of $M^{\prime \prime}(f)$ data to the Origin ${ }^{\circledR}$ non-linear curve fitting tool. The $\tau_{\sigma}$ values were obtained directly from the values of $f_{\sigma}$ by the relation $\tau_{\sigma}=\left(2 \pi f_{\sigma}\right)^{-1}$ [29].

The complex impedance plane plots $\left(Z^{\prime \prime}\right.$ vs. $\left.Z^{\prime}\right)$ are commonly used to separate the bulk material and the electrode surface polarization phenomena $[7,8$, 22-24, 30, 31, 36]. A common feature of dielectrics with dc conductivity is a discontinuity at electrode/dielectric interface, which has different polarization properties with the bulk dielectric material. The frequency dependent values of the real part $Z^{\prime}$ and reactive part $Z^{\prime \prime}$ of the complex impedance $Z^{*}(\omega)$ of the materials were evaluated by the Equation (4) $[30,31]$ :

$$
\begin{aligned}
Z^{*}(\omega)= & \frac{1}{Y^{*}(\omega)}=Z^{\prime}-j Z^{\prime \prime}= \\
& \frac{R_{P}}{1+\left(\omega C_{P} R_{P}\right)^{2}}-j \frac{\omega C_{P} R_{P}^{2}}{1+\left(\omega C_{P} R_{P}\right)^{2}}
\end{aligned}
$$

Figure 3 shows the $Z^{\prime \prime}$ vs. $Z^{\prime}$ plots of the varying MMT clay concentration colloidal suspension in PVP-EG blends. Figure 4 shows the 'master curves representation' [22, 23, 29, 32, 33] of the real and imaginary parts of all the intensive quantities alongwith $\tan \delta$ values of $1 \mathrm{wt} \%$ MMT clay concentration of the solute in PVP-EG blend. It is noticed that the intersection of all the real and imaginary parts of intensive quantities occurs at the same frequency $f_{\sigma}$, and below it direct current $(\mathrm{dc})$ conduction dominates.

\section{Results and discussion}

\subsection{Complex dielectric function spectra}

The increase of clay concentration in the PVP-EG blend gradually increases the $\varepsilon^{\prime}$ and $\varepsilon^{\prime \prime}$ values over the entire frequency spectra (Figure 1). The loading of hydrophilic MMT clay in the PVP-EG blend results the intercalation and exfoliation of the clay sheets. As compared to the intercalation of PVP-EG complex structures, there is larger probability of the intercalation of uncomplexed EG structures in the hydrophilic clay galleries, because EG molecules have smaller size as compared to the PVP monomer units which has a bulky pyrrolidone ring as side 


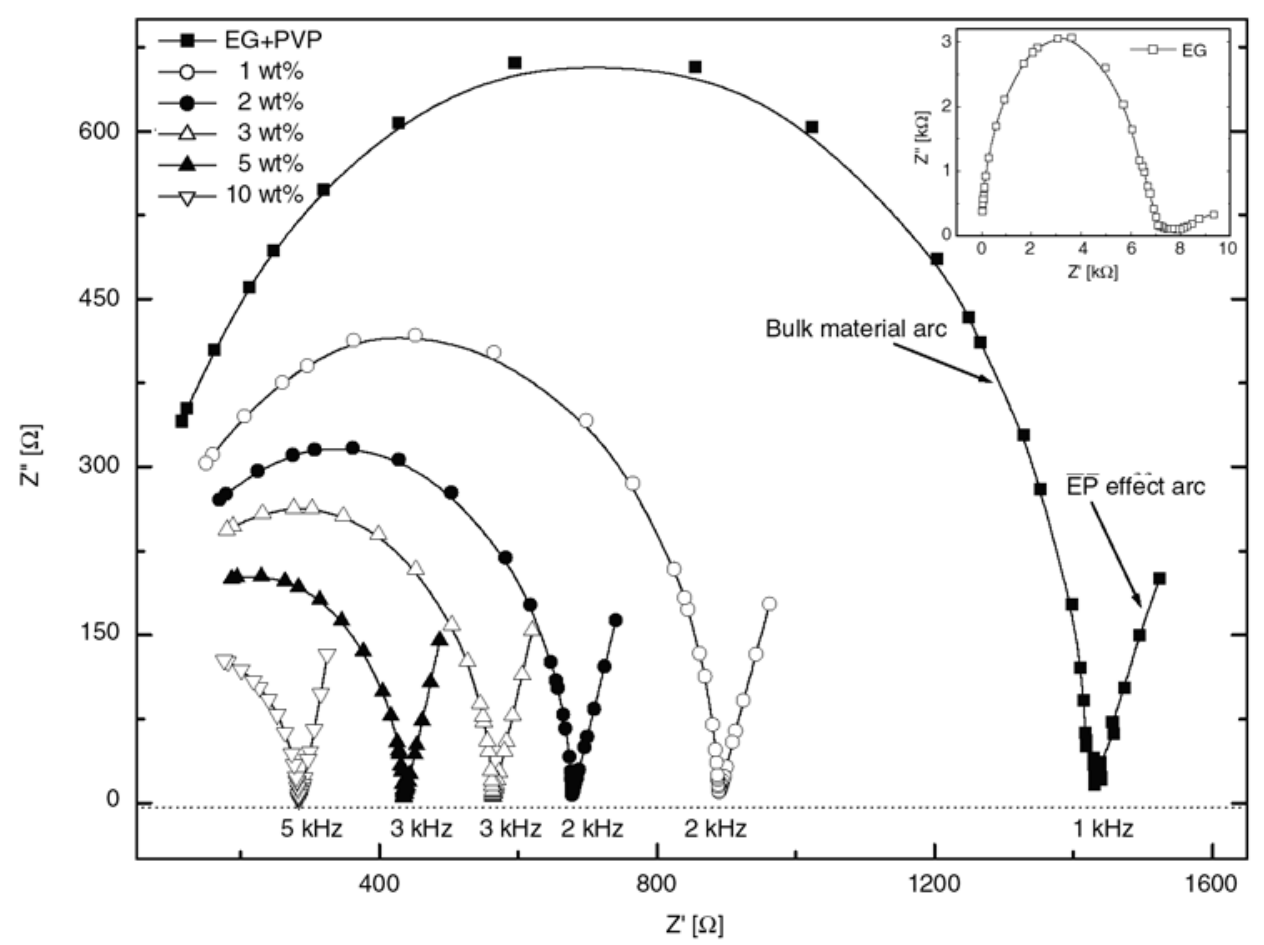

Figure 3. Complex plane plots ( $Z^{\prime \prime}$ vs. $Z^{\prime}$ ) of MMT clay nanoparticles colloidal suspension in PVP-EG blends at varying clay concentration. Inset shows the complex plane plot of pure EG.

group. The adsorption of the PVP-EG complex structures on the clay sheets through $\mathrm{H}$-bond interactions between the hydroxylated aluminate surfaces of the MMT clay and the $\mathrm{C}=\mathrm{O}$ and $-\mathrm{OH}$ groups of PVP-EG blends results the clay exfoliation. The intercalation and exfoliation of MMT clay result both dipolar and free charge in the nanocomposite material, and hence there is increase in the complex dielectric function values [8,9]. Further, the significant increase in $\varepsilon^{\prime}$ and $\varepsilon^{\prime \prime}$ values of these materials with increase of clay concentration may also be related to the formation of a percolation structure of the nanoparticles, which is confirmed by dielectric investigation on nanocomposites [37]. Pure EG, PVP-EG blends and MMT clay loaded PVP-EG blends have a large increase in the $\varepsilon^{\prime}$ values in the lower frequency side of the spectra (Figure 1), which is mainly due to the contribution of the electrode polarization (EP) $[8,21-24]$ and Maxwell-Wanger (MW) interfacial polarization $[38,39]$. Further, the $\varepsilon^{\prime}$ values of the MMT clay loaded PVP-EG blends monotonously increases with the increase of clay concentration, which suggests the enhancement in number of free $\mathrm{Na}^{+}$ cations and their mobility in the increased spacing of intercalated clay galleries.
The EP phenomena occurs due to formation of electric double layer (EDL) capacitances by the free charges build up at the interface between the electrolyte and the electrode surfaces in plane geometry $[32,40]$. Whereas in case of MW phenomena, the free charges build up at the interfacing boundaries of various components of different dielectric constant in the composite dielectric material, which results the nanocapacitors of spherical geometry [38-41]. In EP region, the logarithmic slope of frequency dependent $\varepsilon^{\prime}$ values of the dielectric materials closer to -1 indicate leakiness of the EDL capacitances (blocking layers) to moving charges, whereas value close to 0 suggest a complete block of charge movement through the layers [20, 30, 42, 43]. The slope of the $\varepsilon^{\prime}(f)$ spectra (Figure 1) of the investigated materials closer to -1 suggest the leakiness behaviour of the EDL capacitances formed in the EP region. In general the peak in $\tan \delta$ spectra (Figure 1), which corresponds to electrode polarization (EP) relaxation frequency $\left(f_{E P}\right)$ is used to separate the bulk material and EP phenomenas [29-32]. In the measurements, lower frequency range up to $f_{E P}$, EP polarization dominates the MW polarization.

The $\tau_{E P}$ involves charging and discharging time of EDL capacitance, which is associated with the 


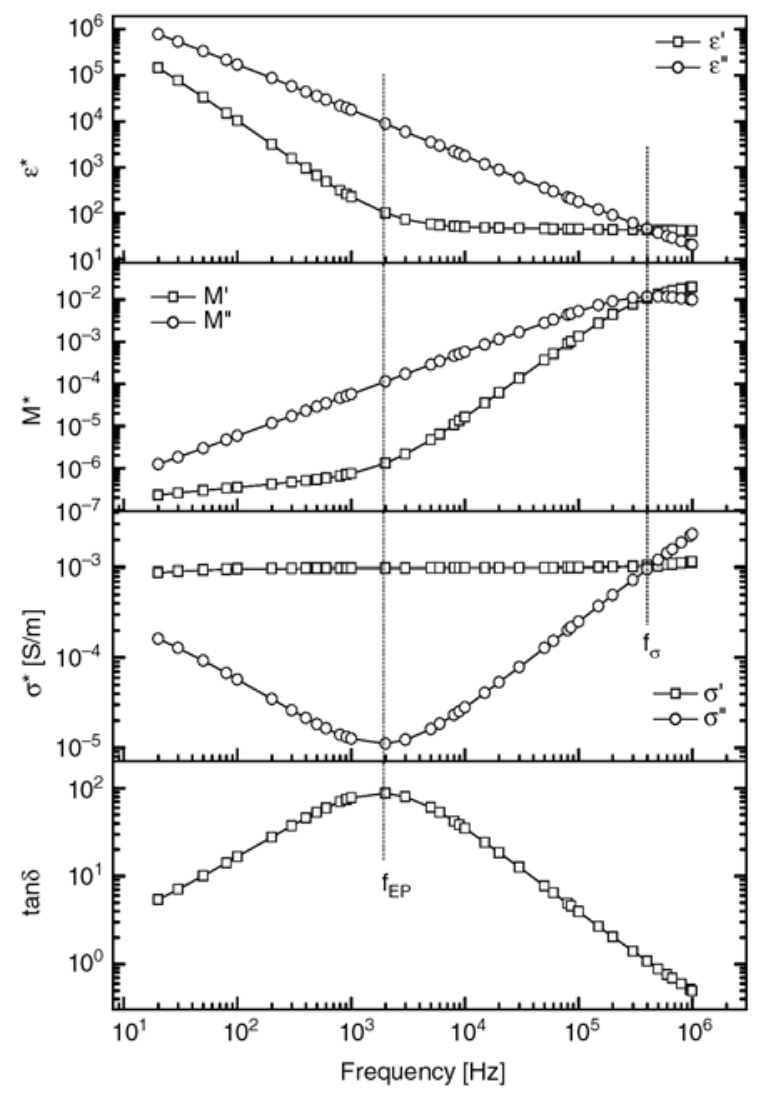

Figure 4. Simultaneous superpositions of the real and imaginary parts of the complex relative dielectric function $\varepsilon^{*}$, the electric modulus $M^{*}$, the complex conductivity $\sigma^{*}$, and loss tangent $\tan \delta$ for MMT clay nanoparticles colloidal suspension in PVP-EG blends with $1 \mathrm{wt} \%$ clay concentration

overall dynamics of the adsorbed ions on the electrode surfaces in the alternating electric field [29-33, 42]. The calculated $\tau_{E P}$ values of the clay loaded PVP-EG blend is plotted against MMT clay concentration [wt\%] in Figure 5. In case of PVPEG blend, the addition of $10 \mathrm{wt} \%$ PVP in EG solvent largely reduces the $\tau_{E P}$ value, which further decreases on loading of MMT clay in PVP-EG blends. The decrease of $\tau_{E P}$ values with increasing clay concentration suggests the faster dynamics of the EDL ions with the variation in the applied alternating electric field.

Inset of Figure 1 shows the $\varepsilon^{\prime}$ dispersion in the upper frequency region of the measurements of the clay loaded PVP-EG blends, which is corresponding to m-process of the PVP chain [21]. The comparative shapes of the m-process in the inset shows that the colloidal suspension of MMT clay nanoparticles in PVP-EG blends significantly influences the PVP local chain motion. Due to limita-

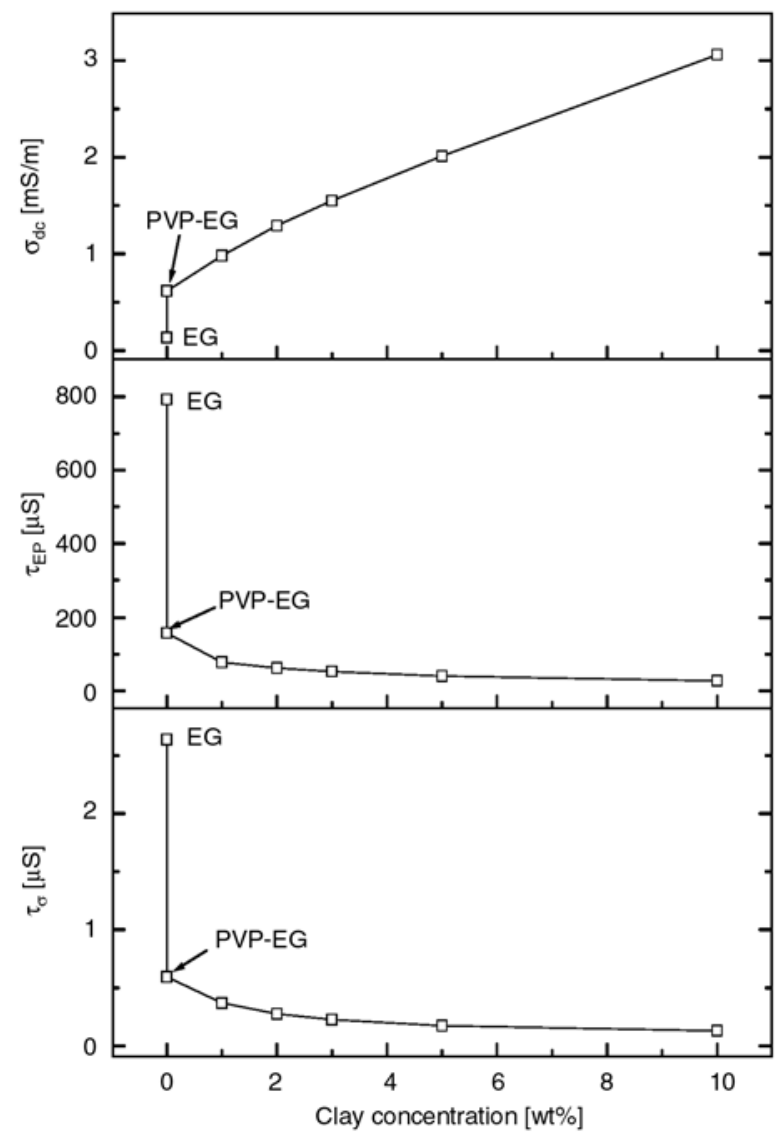

Figure 5. MMT clay concentration dependence of the dc conductivity $\sigma_{d c}$, the electrode polarization relaxation time $\tau_{E P}$ and ionic conduction relaxation time $\tau_{\sigma}$ of MMT clay nanoparticles colloidal suspension in PVP-EG blends

tions of experimental upper frequency range, the relaxation time of m-process could not be evaluated because the inset spectra cover only the starting shoulder of the m-process dispersion.

\subsection{AC conductivity spectra}

The $\sigma^{\prime}$ spectra of the MMT clay loaded PVP-EG blends have frequency independent plateau (Figure 2), which corresponds to ionic or dc electrical conductivity $\sigma_{d c}$ and exhibits dispersion at higher frequencies. This behaviour obeys Jonscher [34] power law $\sigma^{\prime}(\omega)=\sigma_{d c}+A \omega^{n}$, where $A$ is the preexponential factor and $n$ is the fractional exponent ranging between 0 and 1 for the electrolyte. The solid line in the $\sigma^{\prime}$ spectra denotes the fit of experimental data to the power law expression and the fit values of $\sigma_{d c}, A$ and $n$ obtained by Origin ${ }^{\circledR}$ non-linear curve fitting software are recorded in Table 1. The evaluated $\sigma_{d c}$ values of these materials are also 
Table 1. Parameters obtained from fit to the experimental data to $\sigma^{\prime}(\omega)=\sigma_{d c}+A \omega^{n}$ of various clay concentration MMT clay-(PVP-EG) blends

\begin{tabular}{|c|c|c|c|}
\hline MMT clay $[\mathbf{w t} \%]$ & $\boldsymbol{\sigma}_{\mathbf{d c}} \mathbf{1 0}^{\mathbf{3}}[\mathbf{S} / \mathbf{m}]$ & $\mathbf{A} \cdot \mathbf{1 0}^{\mathbf{7}}$ & $\mathbf{n}$ \\
\hline $\mathrm{EG}$ & 0.12 & 3.77 & 0.77 \\
\hline 0 & 0.60 & 3.40 & 0.84 \\
\hline 1 & 0.97 & 3.43 & 0.84 \\
\hline 2 & 1.27 & 3.27 & 0.85 \\
\hline 3 & 1.52 & 3.35 & 0.85 \\
\hline 5 & 1.96 & 3.14 & 0.86 \\
\hline 10 & 2.97 & 3.59 & 0.87 \\
\hline
\end{tabular}

plotted against clay concentration [wt $\%$ ] in Figure 5. The small deviation from $\sigma_{d c}$ (plateau region) value in lower frequency side of the conductivity spectra is evidence of EP effect for these materials, whereas the small dispersion in higher frequency end of the $\sigma^{\prime}$ spectra is owing to the contribution of PVP segmental motion. The $n$ values of these materials are found in the range 0.77 to 0.87 (Table 1). For electrolyte $n$ value can be between 1 and 0.5 indicating the ideal long-range pathways and diffusion limited hopping (tortuous pathway), respectively [44].

It is known that in an electrolyte the electrical conductivity $\sigma$ is given by the relation $\sigma=\Sigma n_{i} \mu_{i} q_{i}$, where $n_{i}, \mu_{i}$ and $q_{i}$ refer to charge carrier density, ionic mobility, and ionic charge of $i^{\text {th }}$ ion respectively [40]. The increase of ionic conductivity of a complex system is due to the increment of the number of mobile charge carriers introduced/produced in the material with the change in concentration of the constituent. In the polymer-clay nanocomposite materials, there is existence of three $\mathrm{H}$-bond phases, namely organic polymer phase, inorganic polymer phase (some tactoids of agglomerated clay nanocomposites) and organic and inorganic components phase [45]. The structural properties and dynamical behaviour of these phases governs the electrical conductivity of the organic-inorganic nanocomposite [45].

The PEO-clay and PEG-clay nanocomposites are extensively attempted to make potential electrolyte material for rechargeable batteries [8, 9, 46-52]. Different spectroscopy investigation on poly(ethylene oxide) PEO-clay nanocomposites [46] confirmed that the intercalated PEO molecules between silicate galleries impede the polymer crystallization, which results in higher electrolyte conductivity compared to the system without clay. In regard to the structural behaviour of the PEO-MMT clay nanocomposites, it was postulated that the PEO chains exist in helical structure in the intercalated state, forming some kind of tunnel that increases the mobility of the cations, and hence also the electrical conductivity [47]. The XRD study of these materials confirmed that the intercalated oxyethylene units are arranged in flattened monolayer arrangements with $4 \AA$ interlayer expansions [5]. It is supported by trans conformation to at least a portion of $\left(\mathrm{O}-\mathrm{CH}_{2}-\mathrm{CH}_{2}-\mathrm{O}\right)$ groups of the PEG chain [48]. Furthermore, the main driving force for the intercalation reaction results from orientation of the polymer chains such that they form hydrogen bond with the hydroxylated aluminate surfaces of the clay. For the maximum hydrogen bonding interaction, the PEG polymer adopts a conformation such that its oxygen matches up with the surface hydroxyl groups of the clay. For this the distances between oxygens in the polymer chain is roughly comparable to the distances between hydroxyl groups in clay sheets.

For clay, interhydroxyl distance is $\sim 2.8 \AA$, and the oxyethylene group repeat every $2.8 \AA$ all facing towards the surface of clay would be particularly favourable [48]. In case of MMT clay colloidal suspension in PVP-EG blends, the intercalated EG structures can be assumed like the intercalated PEG and PEO structures, because the EG molecules have repeat units of PEG and PEO molecules. The investigation on PVP-MMT clay confirmed that the $\mathrm{H}$-bonding interaction between $\mathrm{C}=\mathrm{O}$ groups of PVP chain and $-\mathrm{OH}$ on the silicate surfaces result the large clay exfoliation in PVP-clay nanocomposites, which enhances the nanocomposite thermal property [53]. Considering all the above said facts, in the present investigation, the large enhance in $\sigma_{d c}$ values of the MMT clay loaded PVP-EG blends confirms that besides the increase of charge carriers density, there is significant enhance of structural symmetry which results the easy ionic conduction path. Such path in complex system facilitates the ions mobility and hence their large increase in $\sigma_{d c}$ values of these materials with the increase of clay concentration (Figure 5).

\subsection{Electric modulus spectra}

The $M^{\prime}$ spectra of the clay loaded PVP-EG blend, which are free from space charge effect shows a large dispersion in the ionic conduction region 
(above $f_{E P}$ ) (Figure 2), whereas $M^{\prime \prime}$ spectra shows the relaxation peaks for the conductivity relaxation processes. This suggests that ionic motion and PVP segmental motion are strongly coupled manifesting peak in the $M^{\prime \prime}$ spectra with no corresponding feature in dielectric spectra (Figure 1). Figure 4 shows the 'master-curves representation' of the intensive quantities of $1 \mathrm{wt} \%$ clay colloidal suspension in PVP-EG blend as one of the representative plot. Such plots are frequently used to find out the common intersection frequency $f_{\sigma}$ of the real and imaginary parts of all intensive quantities in the ion conduction region [22-24, 29], which is corresponding to Maxwell-Wagner or ionic conductivity relaxation processes. In the conductivity spectra, $f_{\sigma}$ value separates the change in ions from dc to ac transport. Figure 5 shows the $\tau_{\sigma}$ values $\left[\tau_{\sigma=}\left(2 \pi f_{\sigma}\right)^{-1}\right]$ of these materials which decrease with increase of clay concentration.

Bur et al. [54] applied the $f_{\sigma}$ (also known as $f_{M W}$ ) values for real-time measuring the extent of clay exfoliation during the polymer-clay nanocomposites process. They observed that $f_{\sigma}$ value has the dependence upon the amount of the clay aggregate, intercalated or exfoliated state or any combination thereof. As exfoliation proceeds, nanosize silicate flakes present an ever expanding polymer/clay interface area that increases the internal capacitance of the composite where conducting ions can accumulate. Silicate flakes act as nanocapacitors in the melt polymer. In general, the MW relaxation time $\tau_{\sigma}\left(\tau_{M W}\right)$ can be viewed as an electrical $R C$ time constant where $R$ is the resistance of the polymer matrix and $C$ is the capacitance of the silicate particle. The decrease of $\tau_{\sigma}$ value with increase of clay concentration in PVP-EG blends suggest that the dynamics of the colloid suspension charges increases, which may be due to the extent of clay exfoliation in dynamic equilibrium. The $\mathrm{H}$-bond interfacial bridging of exfoliated clay platelets with $\mathrm{C}=\mathrm{O}$ groups and $-\mathrm{OH}$ groups of PVP-EG blend results the faster dynamics.

\subsection{Complex impedance spectra}

The frequency value of the experimental points increases on going from right to left side on the arcs of the complex impedance plane plot ( $Z^{\prime \prime}$ vs. $Z^{\prime}$ ) of the MMT clay colloidal suspension in PVP-EG blend (Figure 3). All these plots have two separate arcs, which are corresponding to the bulk material effect (the upper frequency arc) and the electrode surface polarization (the lower frequency arc) $[7,8$, 22-24, 36, 55]. Pure EG also have similar type of arcs with comparatively large values of $Z^{\prime \prime}$ and $Z^{\prime}$, and it is shown in the inset of Figure 3. The frequency values correspond to $Z^{\prime \prime}$ minimum value in the plots separates the bulk material and electrode polarization phenomena. These values are also marked in the same Figure. These values are exactly equal to the $\tan \delta$ peak frequency $f_{E P}$. In complex impedance plane plots the extrapolated intercept on the real axis $Z^{\prime}$ of the common part of two arcs gives the value of $d c$ bulk resistance $R_{d c}$, of the dielectric material $[7,8,55]$. It is observed that the $R_{d c}$ value of these materials decreases with the increase of MMT clay concentration, and hence the $\sigma_{d c}$ values increases.

\section{Conclusions}

The dielectric dispersion behaviour and relaxation processes of MMT clay nanoparticles colloidal suspension in PVP-EG blends were investigated in the $20 \mathrm{~Hz}$ to $1 \mathrm{MHz}$ frequency range. Two relaxation processes corresponding to ionic conduction and electrode polarization phenomena and the starting shoulder of PVP segmental motion were observed. The comparative analysis of the various dielectric/ electrical quantities spectra confirms that the behaviour of ionic conduction and EDL dynamics is governed by the MMT clay concentration in these colloidal materials. The type of H-bonding interactions between the MMT clay and the PVPEG blends and clay intercalation and exfoliation were recognized by comparative study of the intensive dielectric quantities. The dc conductivity of these materials can be tailored in the predicted manner with the change in MMT clay concentration, for their potential use as electrolyte material and other technological applications.

\section{Acknowledgements}

Authors are grateful to the Department of Science and Technology, New Delhi for providing the experimental facilities through project No. SR/S2/CMP-09/2002. One of the authors SC is thankful to the University Grants Commission, New Delhi for the award of RFSMS fellowship. 


\section{References}

[1] Feldstein M. M.: Peculiarities of glass transition temperature relation to the composition of poly $(N$-vinyl pyrrolidone) blends with short chain poly(ethylene glycol). Polymer, 42, 7719-7726 (2001).

[2] Li Y., Zhang R., Chen H., Zhang J., Suzuki R., Ohdaira T., Feldstein M. M., Jean Y. C.: Depth profile of free volume in a mixture and copolymers of poly( $N$-vinyl-pyrrolidone) and poly(ethylene glycol) studied by positron annihilation spectroscopy. Biomacromolecules, 4, 1856-1864 (2003).

[3] Feldstein M. M.: Adhesive hydrogels: Structure, properties, and application (A Review). Polymer Science, Series A, 46, 1165-1191 (2004).

[4] Craig D. Q. M.: Dielectric analysis of pharmaceutical systems. Taylor and Francis, London (1995).

[5] Kokabi M., Sirousazar M., Hassan Z. M.: PVA-clay nanocomposite hydrogels for wound dressing. European Polymer Journal, 43, 773-781 (2007).

[6] Ray S. S., Bousmina M.: Biodegradable polymers and their layered silicate nanocomposites: In greening the $21^{\text {st }}$ century material world. Progress in Materials Science, 50, 962-1079 (2005).

[7] Kim S., Hwang E-J., Jung Y., Han M., Park S-J.: Ionic conductivity of polymeric nanocomposite electrolyte based on poly(ethylene oxide) and organo-clay materials. Colloids and Surfaces A, 313-314, 216-219 (2008).

[8] Pradhan D. K., Choudhary R. N. P., Samantaray B. K.: Studies of structural, thermal and electrical behaviour of polymer nanocomposite electrolytes. Express Polymer Letters, 2, 630-638 (2008).

[9] Pradhan D. K., Choudhary R. N. P., Samantaray B. K.: Studies of dielectric relaxation and ac conductivity behaviour of plasticized polymer nanocomposite electrolytes. International Journal of Electrochemical Science, 3, 597-608 (2008).

[10] Bergaya F., Theng B. K. G., Lagaly G.: Handbook of clay science. Elsevier, Amsterdam (2006).

[11] Burmistr M. V., Sukhyy K. M., Shilov V. V., Pissis P., Spanoudaki A., Sukha I. V., Tomilo V. I., Gomza Y. P.: Synthesis, structure, thermal and mechanical properties of nanocomposites based on linear polymers and layered silicates modified by polymeric quaternary ammonium salts (ionenes). Polymer, 46, 1222612232 (2005).

[12] Auad M. L., Nutt S. R., Pettarin V., Frontini P. M.: Synthesis and properties of epoxy-phenolic clay nanocomposites. Express Polymer Letters, 1, 629-639 (2007).

[13] Pannirselvam M., Genovese A., Jollands M. C., Bhattacharya S. N., Shanks R. A.: Oxygen barrier property of polypropylene-polyether treated clay nanocomposite. Express Polymer Letters, 2, 429-439 (2008).

[14] Fritzsche J., Das A., Jurk R., Stöckelhuber K. W., Heinrich G., Klüppel M.: Relaxation dynamics of carboxylated nitrile rubber filled with organomodified nanoclay. Express Polymer Letters, 2, 373-381 (2008).
[15] Das A., Jurk R., Stöckelhuber K. W., Heinrich G.: Rubber curing chemistry governing the orientation of layered silicate. Express Polymer Letters, 1, 717-723 (2007).

[16] Chow W. S., Yap Y. P.: Optimization of process variable on flexural properties of epoxy/organo-montmorillonite nanocomposite by response surface methodology. Express Polymer Letters, 2, 2-11 (2008).

[17] Mishra S. B., Luyt A. S.: Effect of organic peroxide on the morphological, thermal and tensile properties of EVA-organoclay nanocomposites. Express Polymer Letters, 2, 256-264 (2008).

[18] Manoratne C. H., Rajapakse R. M. G., Dissanayake M. A. K. L.: Ionic conductivity of poly(ethylene oxide) (PEO)-montmorillonite (MMT) nanocomposites prepared by intercalation from aqueous medium. International Journal of Electrochemical Science, 1, 32-46 (2006).

[19] Kremer F.: Dielectric spectroscopy-yesterday, today and tomorrow. Journal of Non-Crystalline Solids, 305, 1-9 (2002).

[20] Kremer F., Schönhals A.: Broadband dielectric spectroscopy. Springer, Berlin (2002).

[21] Shinyashiki N., Sengwa R. J., Tsubotani S., Nakamura H., Sudo S., Yagihara S.: Broadband dielectric study of dynamics of poly(vinyl pyrrolidone)-ethylene glycol oligomer blends. The Journal of Physical Chemistry A, 110, 4953-4957 (2006).

[22] Sengwa R. J., Sankhla S.: Solvent effects on the dielectric dispersion of poly(vinyl pyrrolidone)poly(ethylene glycol) blends. Colloid and Polymer Science, 285, 1237-1246 (2007).

[23] Sengwa R. J., Sankhla S.: Dielectric dispersion study of poly(vinyl pyrrolidone)-polar solvent solutions in the frequency range $20 \mathrm{~Hz}-1 \mathrm{MHz}$. Journal of Macromolecular Science Part B: Physics, 46, 717-747 (2007).

[24] Sengwa R. J., Sankhla S.: Low-frequency dielectric response and chain dynamics study of poly(vinyl pyrrolidone)-poly(ethylene glycol) coexisting twophase polymeric blends. Indian Journal of Engineering and Materials Sciences, 14, 317-323 (2007).

[25] Sengwa R. J., Abhilasha, Mehrotra S. C., Sharma B. R.: A comparative dielectric study of poly(vinyl pyrrolidone) in unlike hydroxyl group number containing polar solvents. Indian Journal of Physics, 78, 1341-1348 (2004).

[26] Sengwa R. J., Sankhla S., Abhilasha: Interaction effect on molecular dynamics of some polar solvents in poly(vinyl pyrrolidone) matrix studied by microwave dielectric relaxation measurements in dilute solutions. Indian Journal of Physics, 79, 879-886 (2005).

[27] Sengwa R. J., Kaur K., Chaudhary R.: Dielectric properties of low molecular weight poly(ethylene glycol)s. Polymer International, 49, 599-608 (2000).

[28] Agilent 16452A: Liquid test fixture - Operation and service manual. Agilent Technologies Ltd., Japan (2000). 
[29] Zhang S., Dou S., Colby R. H., Runt J.: Glass transition and ionic conduction in plasticized and doped ionomers. Journal of Non-Crystalline Solids, 351, 2825-2830 (2005).

[30] Pissis P., Kyritsis A.: Electrical conductivity studies in hydrogels. Solid State Ionics, 97, 105-113 (1997).

[31] Sengwa R. J., Sankhla S.: Dielectric dispersion study of coexisting phases of aqueous polymeric solution: Poly(vinyl alcohol) + poly(vinyl pyrrolidone) twophase systems. Polymer, 48, 2737-2744 (2007).

[32] Klein R. J., Zhang S., Dou S., Jones B. H., Colby R. H., Runt J.: Modeling electrode polarization in dielectric spectroscopy: Ion mobility and mobile ion concentration of single-ion polymer electrolytes. The Journal of Chemical Physics, 124, 144903 (pp 8) (2006).

[33] Sengwa R. J., Sankhla S.: Characterization of ionic conduction and electrode polarization relaxation processes in ethylene glycol oligomers. Polymer Bulletin, 60, 689-700 (2008).

[34] Jonscher A. K.: Dielectric relaxation in solids. Chelsea Dielectric Press, London (1983).

[35] Chanmal C. V., Jog J. P.: Dielectric relaxations in $\mathrm{PVDF} / \mathrm{BaTiO}_{3}$ nanocomposites. Express Polymer Letters, 2, 294-301 (2008).

[36] Thakur A. K., Pradhan D. K., Samantaray B. K., Choudhary R. N. P.: Studies on an ionically conducting polymer nanocomposite. Journal of Power Sources, 159, 272-276 (2006).

[37] Kosmidou Th. V., Vatalis A. S., Delides C. G., Logakis E., Pissis P., Papanicolaou G. C.: Structural, mechanical and electrical characterization of epoxyamine/carbon black nanocomposites. Express Polymer Letters, 2, 364-372 (2008).

[38] Kyritsis A., Pissis P.: Dielectric relaxation spectroscopy in poly(ethylene oxide)/water systems. Macromolecular Symposia, 119, 15-24 (1997).

[39] Noda N., Lee Y-H., Bur A. J., Prabhu V. M., Snyder C. R., Roth S. C., McBrearty M.: Dielectric properties of nylon 6/clay nanocomposites from on-line process monitoring and off-line measurements. Polymer, 46, 7201-7217 (2005)

[40] MacCallum J. R., Vincent C. A.: Polymer electrolyte reviews, vol 1. Elsevier, London (1987).

[41] Garrouch A. A., Lababidi H. M. S., Gharbi R. B.: Dielectric dispersion of dilute suspension of colloid particles: Practical applications. The Journal of Physical Chemistry, 100, 16996-17003 (1996).

[42] Craig D. Q. M., Newton J. M., Hill R. M.: An investigation into the low-frequency dielectric response of polyethylene glycols. Journal of Material Science, 28, 405-410 (1993).
[43] Craig D. Q. M., Barker S. A., Banning D., Booth S. W.: An investigation into the mechanisms of selfemulsification using particle size analysis and low frequency dielectric spectroscopy. International Journal of Pharmaceutics, 114, 103-110 (1995).

[44] Mauritz K. A.: Dielectric relaxation studies on ion motion in electrolyte-containing perfluorosulfonate ionomers. 4. Long range ion transport. Macromolecules, 22, 4483-4488 (1989).

[45] Mamunya Y., Kanapitsas A., Pissis P., Boiteux G., Lebedev E.: Water sorption and electrical/dielectric properties of organic-inorganic polymer blends. Macromolecular Symposia, 198, 449-459 (2003).

[46] Aranda P., Ruiz-Hitzky E.: Poly(ethylene oxide)/ $\mathrm{NH}_{4}^{+}$-smectite nanocomposites. Applied Clay Science, 15, 119-135 (1999).

[47] Reinholdt M. X., Kirkpatrick R. J., Pinnavaia T. J.: Montmorillonite-poly(ethylene oxide) nanocomposites: Interlayer alkali metal behaviour. The Journal of Physical Chemistry B, 109, 16296-16303 (2005).

[48] Tunney J. J., Detellier C.: Aluminosilicate nanocomposite materials. Poly(ethylene glycol)-kaolinite intercalates. Chemical Materials, 8, 927-935 (1996).

[49] Chen W., Xu Q., Yuan R. Z.: The influence of polymer state on the electrical properties of polymer/layered-silicate nanocomposites. Composites Science and Technology, 61, 935-939 (2001).

[50] Liao B., Song M., Liang H., Pang Y.: Polymer-layered silicate nanocomposites. 1. A study of poly(ethylene oxide) $/ \mathrm{Na}^{+}$-montmorillonite nanocomposites as polyelectrolytes and polyethylene-block-poly(ethylene glycol) copolymer/ $\mathrm{Na}^{+}$-montmorillonite nanocomposites as fillers for reinforcement of polyethylene. Polymer, 42, 10007-10011 (2001).

[51] Chaiko D. J.: New poly(ethylene oxide)-clay composites. Chemical Materials, 15, 1105-1110 (2003).

[52] Lin-Gibson S., Kim H., Schmidt G., Han C. C., Hobbie E. K.: Shear-induced structure in polymer-clay nanocomposite solutions. Journal of Colloid and Interface Science, 274, 515-525 (2004).

[53] Koo C. M., Ham H. T., Choi M. H., Kim S. O., Chung I. J.: Characteristics of polyvinylpyrrolidone-layered silicate nanocomposites prepared by attrition ball milling. Polymer, 44, 681-689 (2003).

[54] Bur A. J., Lee Y-H., Roth S. C., Start P. R.: Measuring the extent of exfoliation in polymer/clay nanocomposites using real-time process monitoring methods. Polymer, 46, 10908-10918 (2005).

[55] Wang M., Dong S.: Enhanced electrochemical properties of nanocomposite polymer electrolyte based on copolymer with exfoliated clays. Journal of Power Sources, 170, 425-432 (2007). 